\title{
Risk of Malignancy in Symptomatic Nodular Goiter Treated with Radiofrequency Ablation
}

W e read with great interest the recent article by Che et al. ${ }^{1}$ In this article, the authors compared the efficacy, safety, and cost-effectiveness of surgery versus radiofrequency ablation (RFA) for the treatment of benign thyroid nodules. Two hundred patients were retrospectively selected for each group. The authors assessed procedure-related complications, the length of hospitalization, and cost. In addition, nodule volume, incidence of hypothyroidism, and the rate of residual nodules were assessed at 1-year follow-up. All of these outcomes uniformly favored RFA over surgery; the cost between the 2 procedures was not significantly different. Consequently, the authors advocated RFA as the first-line treatment for benign thyroid nodules.

We commend the authors for conducting the largest retrospective cohort study comparing these 2 treatment options for benign thyroid nodules. However, the result could be significantly confounded by patient-selection bias. The authors used different criterion standards to define benign thyroid nodules in the surgery-versus-RFA groups (surgery pathology and cytology from fine-needle aspiration, respectively). This patient-selection method excluded patients whose nodules were benign by cytology but malignant by surgical pathology in the surgery group. In fact, the potential of mistreating malignant nodules as benign ones is the strongest argument against RFA as the first-line treatment for symptomatic nodular goiter. ${ }^{2}$

Two studies in the literature compared surgery and RFA as a treatment for benign thyroid nodules. One is the current study. ${ }^{1}$ In the other study, the authors found that $8 \%$ of their patients (6 of 74) in the surgical arm were misdiagnosed as having benign nodules. ${ }^{3}$ Surgical pathologies in these patients later revealed malignant cells in their nodules. ${ }^{3}$ RFA did not allow any pathologic analysis of the nodules. On the basis of these results, the authors concluded that RFA was not a safe alternative to surgery for the treatment of hyperfunctioning nodules.

In a related study, Negro et $\mathrm{al}^{4}$ assessed the risk of undiagnosed malignancy in patients with multinodular goiter presumed to

- Indicates open access to non-subscribers at www.ajnr.org

http://dx.doi.org/10.3174/ajnr.A4580 have benign thyroid disease and eligible for nonsurgical treatments. They found that 84 of $970(8.6 \%)$ patients who underwent thyroidectomy had malignancy by histologic examination $(5 \%$ incidental thyroid cancer and 3.6\% false-negative fine-needle aspiration cytology). ${ }^{4}$ Although 67 of these malignant thyroid nodules $(79.8 \%)$ were stage I disease by the American Joint Committee on Cancer criteria, the authors concluded that the risk of malignancy in presumably benign thyroid disease cannot be overlooked.

In another related study of 1161 patients who underwent total thyroidectomy for diffuse multinodular goiter, 252 (21.7\%) were cases of thyroid cancer. ${ }^{5}$ In this study, the sensitivity of thyroid sonography and fine-needle aspiration cytology for cancer detection was only $30.3 \%$ and $64.1 \%$, respectively. By preselecting patients who have benign disease on surgical pathology to compare with the RFA group, the current article effectively bypassed the most important question facing clinicians who need to discuss the pros and cons of the 2 approaches with their patients: What is the risk of a missed malignancy if I choose RFA over surgery? The consequence of such missed malignancy is currently unclear.

In conclusion, a randomized controlled trial is needed to compare the safety and efficacy of surgery versus RFA for the treatment of "benign" nodular goiter. If this is not feasible, long-term follow-up of patients treated with RFA is required before it can be recommended as first-line therapy.

\section{ACKNOWLEDGEMENTS}

This work was supported by the Natural Science Foundation of China (grant number 81301988) to Li Yang, and China Ministry of Education Doctoral Program Spot Foundation (grant number 20130162120061) to Li Yang.

\section{REFERENCES}

1. Che Y, Jin S, Shi C, et al. Treatment of benign thyroid nodules: comparison of surgery with radiofrequency ablation. AJNR Am J Neuroradiol 2015;36:1321-25 CrossRef Medline

2. Arora N, Scognamiglio T, Zhu B, et al. Do benign thyroid nodules have malignant potential? An evidence-based review. World J Surg 2008;32:1237-46 CrossRef Medline

3. Bernardi S, Dobrinja C, Fabris B, et al. Radiofrequency ablation 
compared to surgery for the treatment of benign thyroid nodules. Int J Endocrinol 2014;2014:934595 CrossRef Medline

4. Negro R, Piana S, Ferrari M, et al. Assessing the risk of false-negative fine-needle aspiration cytology and of incidental cancer in nodular goiter. Endocr Pract 2013;19:444-50 CrossRef Medline

5. Lasithiotakis K, Grisbolaki E, Koutsomanolis D, et al. Indications for surgery and significance of unrecognized cancer in endemic multinodular goiter. World J Surg 2012;36:1286-92 CrossRef Medline

Department of Neurology

The Second Xiangya Hospital of Central South University Changsha, China

H. Tang

Department of Radiology

The First Xiangya Hospital of Central South University Changsha, China

A.M. Lee

Department of Radiology Hospital of the University of Pennsylvania Philadelphia, Pennsylvania

Y. Zou

X. Huang

X. Tang

Department of Neurology

The Second Xiangya Hospital of Central South University

Changsha, China

H.X. Bai

Department of Radiology

Hospital of the University of Pennsylvania

Philadelphia, Pennsylvania 